\title{
Synthesis of ZnO Nanoparticles by the Sol-Gel Protein Route: A Viable and Efficient Method for Photocatalytic Degradation of Methylene Blue and Ibuprofen
}

\author{
Emilly C. da Silva, ${ }^{a}$ Maria O. S. de Moraes, ${ }^{a}$ Walter R. Brito, ${ }^{a}$ Raimundo R. Passos, ${ }^{a}$ \\ Rodrigo F. Brambilla, ${ }^{a}$ Luiz P. da Costa ${ }^{\circledR b}$ and Leandro A. Pocrifka ${ }^{\circledR * a}$ \\ ${ }^{a}$ Laboratório de Eletroquímica e Energia (LEEN), Programa de Pós-Graduação em Química, \\ Universidade Federal do Amazonas (UFAM), Av. Rodrigo Otávio, 1200, Coroado, \\ 69067-005 Manaus-AM, Brazil \\ ${ }^{b}$ Instituto de Ciências Exatas e Tecnologicas, Universidade Federal do Amazonas (UFAM), \\ Rua Nossa Senhora do Rosario, 3863, Tiradentes, 69103-128 Itacoatiara-AM, Brazil
}

The photocatalytic degradation of methylene blue dye and ibuprofen drug was studied in the presence of zinc oxide, synthetized by the protein sol-gel route. The catalyst, calcined at $1000{ }^{\circ} \mathrm{C}$, presented a tendentious morphology to filaments characteristic of $\mathrm{ZnO}$ crystalline, characterized by X-ray diffraction (XRD) and confirmed by the presence of Zn energy band in X-ray photoelectron spectrometer (XPS). The result of ultraviolet (UV) light photodegradation of this work is comparable to others that made use of more complex routes, considering the degradation of $97 \%$ of methylene blue dye solution and the solution of the ibuprofen drug reached $60 \%$ of degradation after $1 \mathrm{~h}$ of light incidence. In this research, it is possible to report good degradation results, and the research differential is a material made with a simple and less aggressive route, capable of generating a stable and efficient material.

Keywords: sol-gel protein, photocatalysis, green synthesis

\section{Introduction}

The increasing demand for clean water and the high level of contaminants dumped in various water bodies render the conventional methods of wastewater treatment inefficient. The advanced oxidative processes (AOPs) has been widely studied as an alternative in the treatment of wastewaters due to the low selectivity for molecules and high power of mineralization. ${ }^{1,2}$

Among the several advanced treatments available, the heterogeneous photocatalytic oxidation process has been proposed as a clean and efficient method for the purification of: air, soil, industrial wastewater, groundwater, drinking water and industrial fine chemical production, thanks to many advantages, including destruction efficiency and a wide range of applications at room temperature. ${ }^{3,4}$

Semiconductors such as $\mathrm{ZnO}$ are widely used as promising candidates for photocatalytic degradation reactions. Parameters such as abundance, low cost, nontoxic, high electronic mobility, easy synthesis, besides high photosensitivity and good stability contribute to making

*e-mail: pocrifka@ufam.edu.br
$\mathrm{ZnO}$ one of the most cited materials. ${ }^{4-6} \mathrm{The} \mathrm{ZnO}$ is known as an effective photocatalyst because it absorbs in a wide range of the UV spectrum from $425 \mathrm{~nm}$ and has energy gap $(\mathrm{Eg})=3.37 \mathrm{eV}^{4-7}$

Many of the semiconductors used have broad band gap values that can be excited only under UV light irradiation, while studies show the effective activity of $\mathrm{ZnO}$ for the photodegradation of organic pollutants using sunlight. ${ }^{8,9}$ The adaptation of $\mathrm{ZnO}$ materials can reduce costs and improve performance in order to inhibit recombination of the surface charge carrier. ${ }^{8}$

There are several methods for adapting $\mathrm{ZnO}$ materials, such as creating defects in oxide structure by doping with hetero molecules, noble metals or other semiconductors. ${ }^{9}$

Many routes have been improved to prepare the photocatalyst, such as a chemical vapor deposition, ${ }^{10}$ hydrothermal impregnation, ${ }^{11}$ sol-gel, ${ }^{12}$ etc. The sol-gel method is used in the preparation of various materials and is an effective method because it facilitates stoichiometric control, porosity, crystalline structure and even particle size. Therefore, the materials obtained by this method have high purity, homogeneity and lower processing temperatures when compared with those formed by other methods. ${ }^{13}$ 
The sol-gel protein route consists of synthesizing nanometric powders at relatively low temperatures, simple to perform and low cost, the principle of which is to use gelatin as an organic driver, replacing citric acid and ethylene glycol, generally used in other syntheses. ${ }^{14}$

In sol-gel protein route, the process of producing gels is divided in two steps: hydrolysis and condensation. In the sol-gel protein route these steps occur when some of the constituents of the gelatin bind to the metal. ${ }^{15}$

The sol-gel protein route, in addition to being environmentally friendly and low cost, makes use of progressively increasing supports, viscosity and elasticity, creating a 3D structure to support metal particles and the unwanted components of these supports are easily eliminated with increasing temperature. ${ }^{15}$

In this study it is possible to see the efficiency of zinc oxide, prepared by sol-gel protein route, in the degradation of a solution of dye and of a drug when synthesized via sol-gel protein.

To complex the metal the use of commercial gelatin is made and the synthesized material was calcined at $1000^{\circ} \mathrm{C}$ to guarantee the cleaning of organic residues.

\section{Experimental}

\section{Synthesis of $\mathrm{ZnO}$ nanoparticles}

The sol-gel protein synthesis was similar to that used by Etcheverry et al.,$^{15}$ performed with $1 \mathrm{~g}$ of zinc nitrate $\left(\mathrm{Zn}\left(\mathrm{NO}_{3}\right)_{2} \cdot 6 \mathrm{H}_{2} \mathrm{O}\right.$, Sigma-Aldrich, Manaus, Brazil) as an organometallic compound, added to $2 \mathrm{~g}$ of commercial gelatin for the gelatinization. The ratio of the metal precursor and gelatin mass was 1:2, homogenized in $200 \mathrm{~mL}$ of aqueous $\mathrm{KOH}$ (Sigma-Aldrich, Manaus, Brazil) solution for $50 \mathrm{~min}$. After this step, the material was dried at $100{ }^{\circ} \mathrm{C}$ for $24 \mathrm{~h}$ to obtain a resin. The resin formed was calcined at $1000{ }^{\circ} \mathrm{C}$ for $2 \mathrm{~h}$.

\section{Characterization}

The obtained powder was characterized by X-ray diffraction (XRD) using X-ray Shimadzu, model XRD 7000 , using $\mathrm{Cu} \mathrm{K} \alpha(\lambda=1.54056 \AA)$. The diffractograms were recorded in $2 \theta$ in the range of 30 to $40^{\circ}$, with step size of $0.05^{\circ}$ and scan time of $2 \mathrm{~s}$ per step.

Scanning electron microscopy (SEM) was performed using a microscope model Vega3 Tescan. The sample preparation was carried out by fixing the calcined powder on a carbon tape superimposed on an aluminum stub. The sample was previously metallized in a Bal-Tec SCD 050 Sample Sputter Coater.
The atomic ratios of the synthesized materials were measured by using X-ray photoelectron spectrometer (XPS) K-Alpha (Thermo Scientific).

\section{Photocatalytic degradation}

The study of the photocatalytic activity of the $\mathrm{ZnO}$ nanoparticles was based on the degradation of the methylene blue dye $\left(\mathrm{C}_{16} \mathrm{H}_{18} \mathrm{~N}_{3} \mathrm{ClS} . \mathrm{H}_{2} \mathrm{O}\right.$, Nuclear $98 \%$, Manaus, Brazil) and the ibuprofen drug, $\left(\mathrm{C}_{13} \mathrm{H}_{18} \mathrm{O}_{2}\right.$, SigmaAldrich 98\%, Manaus, Brazil), both prepared in aqueous solution $\left(20 \mathrm{mg} \mathrm{L}^{-1}\right)$. The degradation system was set up under UV light irradiation $254 \mathrm{~nm}, 100 \mathrm{Wm}^{-2}$ at $25^{\circ} \mathrm{C}$ and the catalyst rate per $\mathrm{mL}$ of solute was 1:1.

The photocatalytic activity experiments were performed in a bench reactor: an ultraviolet light exposure box, where the contaminant solution is inserted into a beaker, together with the prepared catalyst and is exposed for certain periods of time to light.

The measurement of concentration indices of the pollutant solutions was analyzed using the UV spectrophotometer from Thermo-Scientific Evolutions 300, using a quartz cuvette with $1 \mathrm{~cm}$ optical path. The spectra were scanned and also analyzed punctually with a fixed wavelength at $664 \mathrm{~nm}$, corresponding to the absorption of the methylene blue dye and at $200 \mathrm{~nm}$ corresponding to the absorption of the drug ibuprofen.

The degradation rate of the dye and the drug $(\mathrm{X} \%)$ was calculated as a function of time and given as a percentage as shown in equation 1 .

$X(\%)=\left[\frac{C_{0}-C_{f}}{C_{0}}\right] \times 100$

where $\mathrm{C}_{0}$ represents the initial concentration of the solution and $\mathrm{C}_{\mathrm{f}}$ represents the concentration of the solution after determined time of irradiation.

\section{Results and Discussion}

\section{Characterization of synthesized $\mathrm{ZnO}$}

To determine the morphology and particle size of the material produced, SEM analyzes were performed. Figure 1 shows the micrograph of the sample where it is possible to observe that there are some elongated structures in the form of rods with lengths on the order of $5 \mu \mathrm{m}$, in the middle of an amorphous, porous and poorly defined shape.

The image shows that the samples are nanoparticulate in the order of $21 \mathrm{~nm}$ and, when compared to work using a distinct synthetic route, the sol-gel protein route 
presents certain advantage having smaller particle size. Zhang et al. ${ }^{16}$ for example, produced by the precipitation method, a material with a mean size of $300 \mathrm{~nm}$ at temperature of $1150{ }^{\circ} \mathrm{C} .{ }^{16}$

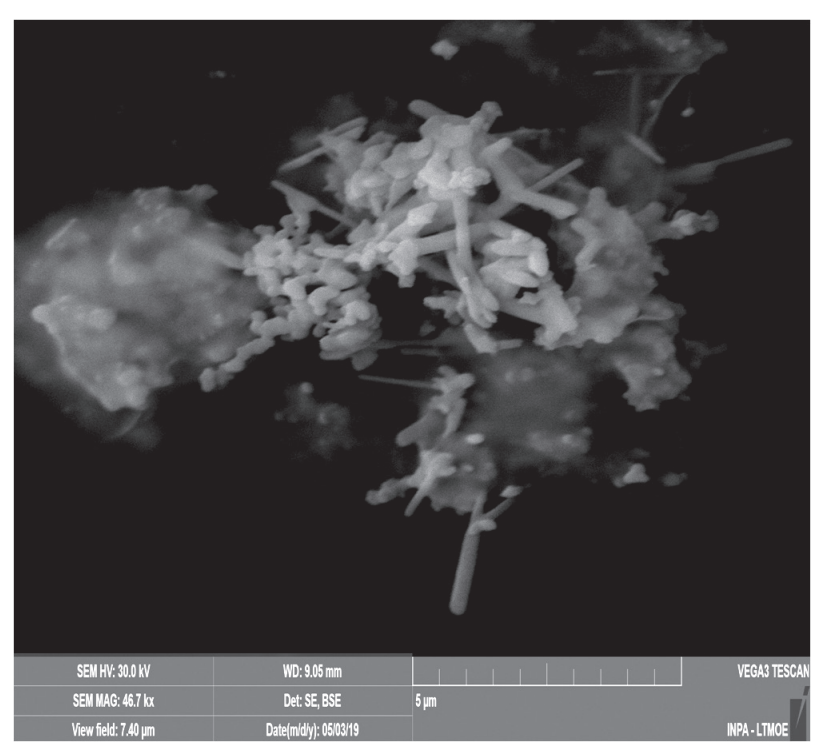

Figure 1. Electron microscopy image of the sample obtained with secondary electrons in backscattering mode.

XRD pattern for the $\mathrm{ZnO}$ material, introduced in Figure 2, shows that $\mathrm{ZnO}$ is the predominant phase, characterized by peaks of ca. 32,34 and $36^{\circ}$ according to JCPDF No. 89510. The XRD patterns were refined using the Pawley method ${ }^{17}$ with the Fityk 0.98 software ${ }^{18}$ for more information about these peaks in relation to the network parameters. It was found that the network parameters for $\mathrm{ZnO}$ were $\mathrm{a}=3.251$ and $\mathrm{c}=5.214$, results close to those reported on the JCPDF reference card No. 89510.

Analyzing XRD measurements it was also possible to estimate the average crystallite size of $\mathrm{ZnO}$ by the Scherrer

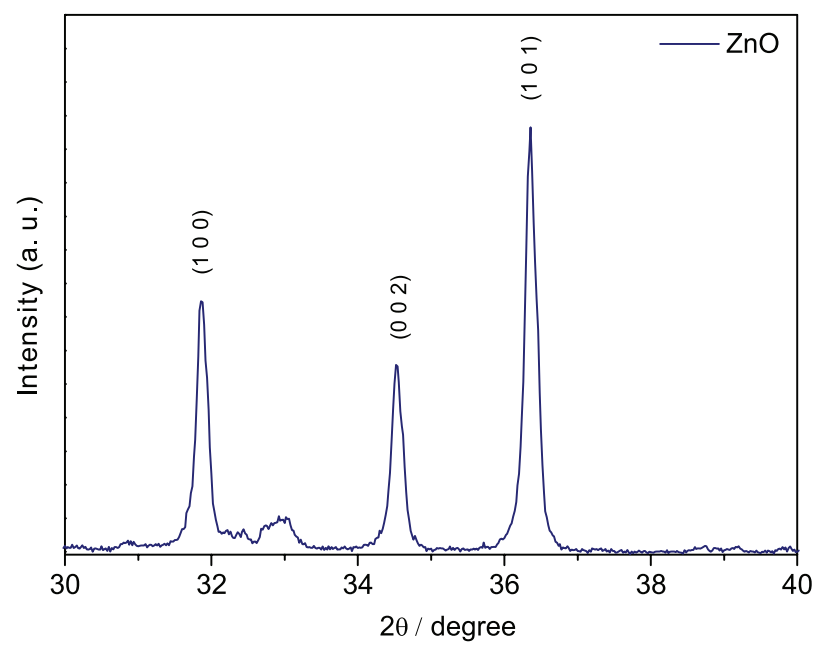

Figure 2. XRD pattern of the $\mathrm{ZnO}$ material. equation, ${ }^{15}$ obtaining the value of $21.1 \mathrm{~nm}$ for the heat treatment at temperature of $1000{ }^{\circ} \mathrm{C}$.

The results show that the desired crystalline phase wurtzite is present in the material, confirming that the elongated peak is associated with crystallization events. Based on these analyzes it can be stated that the sol-gel protein method is efficient for the production of zinc oxide.

In Figure 3a, a typical spectrum of XPS for the Zn2p region was observed for the $\mathrm{ZnO}$ nanoparticles with the presence of a doublet due to the spin-orbit coupling. The peak centered at $1044.1 \mathrm{eV}$ was attributed to $\mathrm{Zn} 2 \mathrm{p}_{1 / 2}$ and the peak centered at $1021.0 \mathrm{eV}$ was attributed to $\mathrm{Zn} 2 \mathrm{p}_{3 / 2}$ indicating that the $\mathrm{Zn}$ valence at the surface of the $\mathrm{ZnO}$ nanotubes is the oxidation state $2+$. The energy of separation between the peaks was $23 \mathrm{eV}$ according to the literature. ${ }^{19}$ Figure $3 \mathrm{~b}$ shows the XPS spectrum of the O1s region deconvolved in two Gaussian curves indicating the presence of two chemical species around the oxygen atom. Two Gaussian curves labeled as $(\mathrm{Zn}-\mathrm{OH})$ and $(\mathrm{Zn}-\mathrm{O})$ were used to adjust the experimental data.

The adjusted gaussian curve $(\mathrm{Zn}-\mathrm{OH})$ showed a binding energy at $530.6 \mathrm{eV}$ attributed to the $\mathrm{O}^{2-}$ ions in the $\mathrm{Zn}-\mathrm{O}$ bonding of the wurtzite structure of hexagonal $\mathrm{ZnO} .^{20,21} \mathrm{The}$ other curve $(\mathrm{Zn}-\mathrm{O})$ located at $531.7 \mathrm{eV}$ is related to the $-\mathrm{OH}$ group absorbed on the surface of the $\mathrm{ZnO}$ nanotubes ${ }^{22,23}$ and the presence of carbonates was not observed.

\section{Photocatalytic activity of the material}

Figures $4 \mathrm{a}$ and $4 \mathrm{c}$ show results of degradation of methylene blue (MB) and ibuprofen (IB) for 60 min under ultraviolet light $(254 \mathrm{~nm})$ and with aliquots as a function of time, it was possible to verify a high degradation capacity.

Looking at the figures, it is possible to observe the reduction of the main MB peaks $\left(\lambda_{\max }=664 \mathrm{~nm}\right)$ and IB $\left(\lambda_{\max }=200 \mathrm{~nm}\right)$ occurring as the irradiation time increases, this characteristic is attributed to the $\pi$-conjugated system break of the dye and the drug structure, during the photocatalytic test. This indicates a rupture in the chromophore structure of the pollutants. ${ }^{6,7}$

For the ultraviolet light degradation test, the catalyst material was immobilized on a carbon plate, measuring $1 \times 1 \mathrm{~cm}$, so it can be reused with recovery of its total mass.

Photolysis tests can be observed in the Figures $4 \mathrm{~b}$ and $4 \mathrm{~d}$, which allow the conclusion that there is no significant influence of light on the degradation of the dye and also on the degradation of the drug. ${ }^{8,9}$

In the photocatalysis tests, $\mathrm{ZnO}$ and the pollutant solutions were first stirred in the dark during the $30 \mathrm{~min}$ interval to achieve the adsorption-desorption equilibrium between the photocatalyst and the dye, as can be seen in 

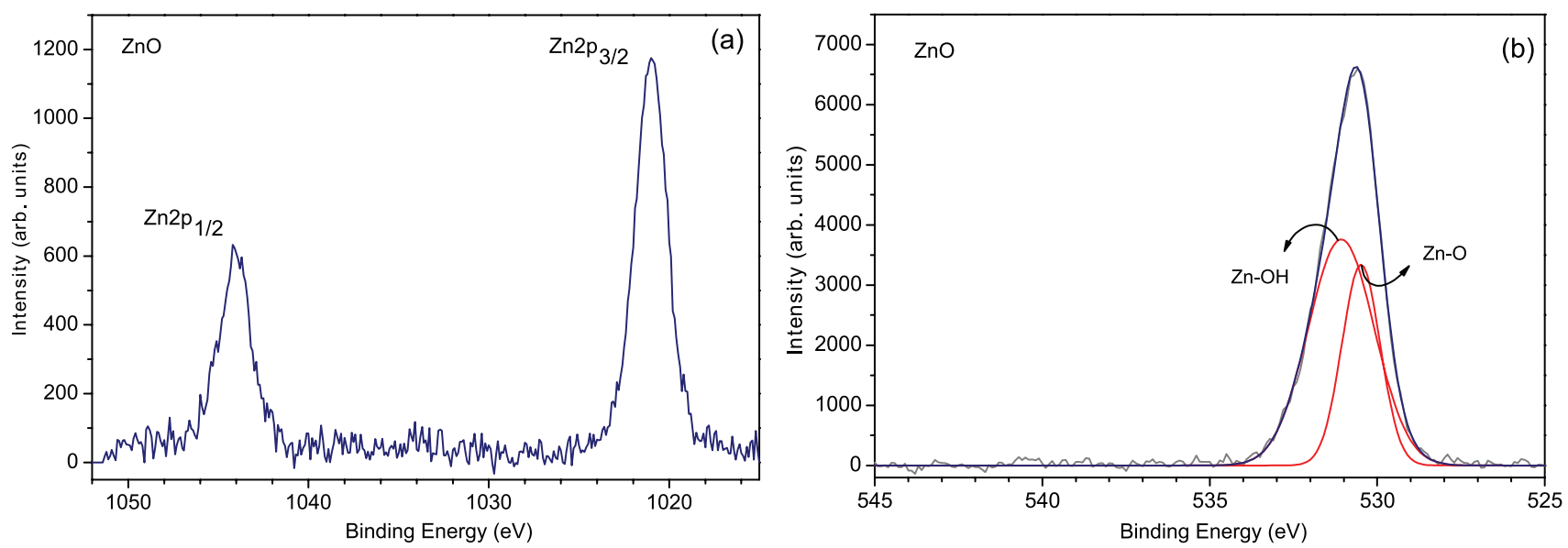

Figure 3. High-resolution XPS spectra of $\mathrm{Zn} 2 \mathrm{p}$ (a) and $\mathrm{O} 1 \mathrm{~s}$ (b) of $\mathrm{ZnO}$ nanoparticles synthesized via protein sol-gel method and calcined at $1000{ }^{\circ} \mathrm{C}$.
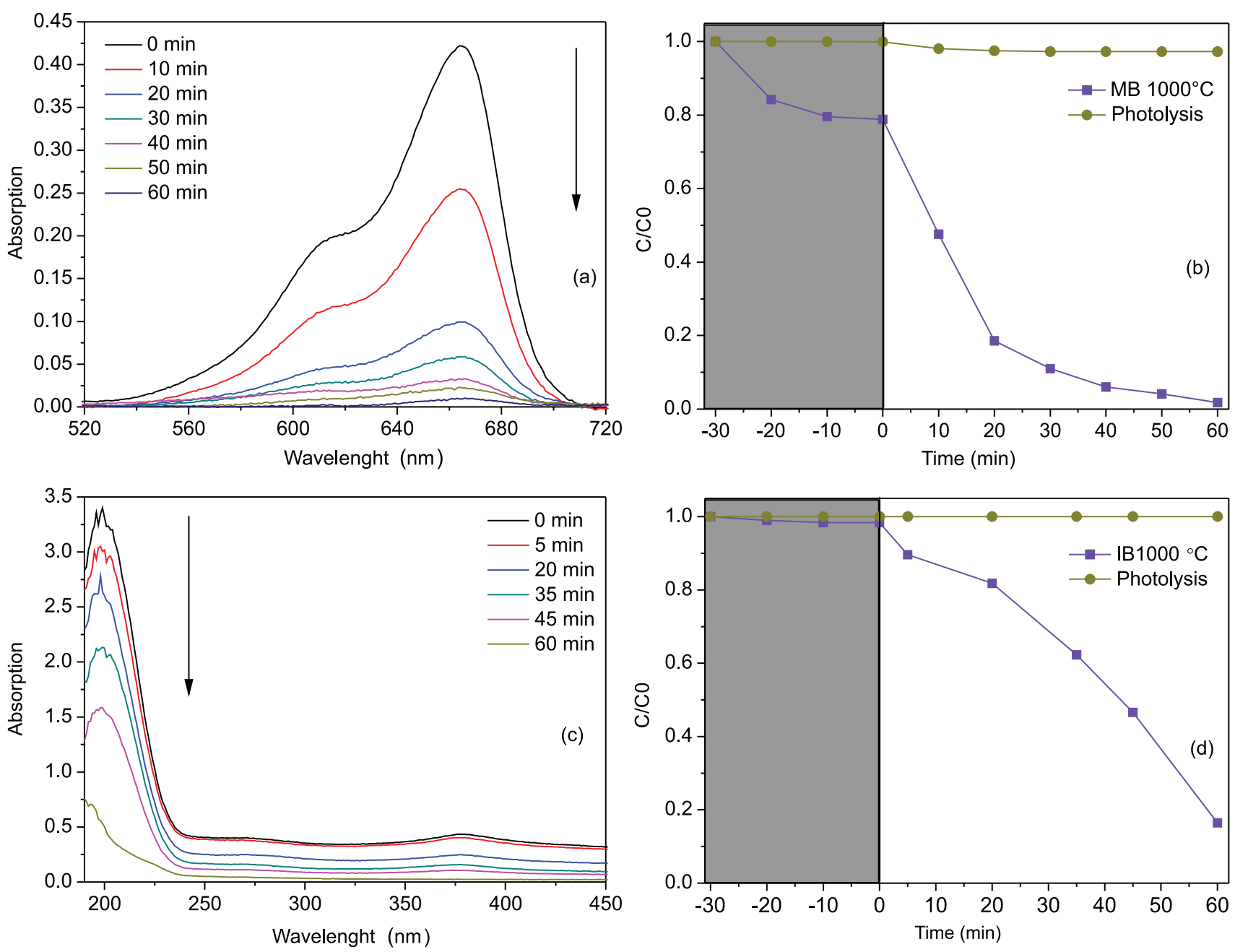

Figure 4. Degradation graphs via photocatalysis. (a) Scanning of the spectrum of methylene blue degradation in the presence of the catalyst, (b) behavior of the degradation process at the point of greatest absorption of methylene blue at $664 \mathrm{~nm}$, along with the first thirty minutes that the catalyst was placed in the dark for adsorption testing, (c) scanning of the spectrum of the degradation of ibuprofen in the presence of the catalyst, (d) behavior of the degradation process at the point of greatest absorption of ibuprofen at $200 \mathrm{~nm}$, along with the first thirty minutes that the catalyst was placed in the dark for adsorption testing.

the Figures $4 \mathrm{~b}$ and $4 \mathrm{~d}$. The concentration of the solution after this equilibrium was taken as the initial concentration of MB and IB for the degradation studies.
It is observed that the adsorption of the materials does not exceed the $25 \%$ margin and enters stability after $20 \mathrm{~min}$ of total darkness, collaborating with a degradation of the 
Table 1. Data regarding the use of $\mathrm{ZnO}$ as a pollutant photocatalyst in other researches

\begin{tabular}{lcccc}
\hline Reference & Material & Solution & Degradation / \% & time / h \\
\hline 23 & graphene/ZnO-nanofibers & methylene blue & 80 & 4.0 \\
24 & ZnO-nanofibers & methylene blue & 47 & 3.3 \\
25 & ZnO-nanoflowers & rhodamine b & 80 & 1.3 \\
26 & ZnO-nanoparticles & dibenzothiophene & 97 & 3.3 \\
27 & ZnO-nanoparticles & ciprofloxacin & 50 & 1.0 \\
\hline
\end{tabular}

material through the heterogeneous photocatalysis. These percentages are important for the catalysis process, but they are not primarily responsible for the complete degradation of the material, making it possible to conclude that the catalyst is responsible for the degradation of more than half of the pollutant concentration of the agent.

The zinc oxide catalyst, synthesized via protein sol-gel, produced a degradation of $97 \%$ in the MB dye solution (see Figure $4 \mathrm{~b}$ ) and $60 \%$ of the drug solution IB(see Figure $4 d$ ).

This higher activity can be explained by the following hypothesis: $\mathrm{ZnO}$ calcination allows the formation of a material with a low content of impurities, which favors the electronic transitions in the generation of radicals that degrade the dye and the drug. ${ }^{19}$

The $\mathrm{ZnO}$ synthesized presented a catalytic activity superior to $60 \%$ of degradation, due to its crystalline size estimated at $21.1 \mathrm{~nm}$, which gives it greater contact area. It was possible to observe the $\mathrm{ZnO}$ phase according to XRD and XPS; and the tendency of nanotubes formation in SEM images, that gives the material a greater efficiency of the process of degradation of the pollutant solution, since there is no significant intervention of other species.

The general mechanism of photocatalysis ${ }^{3}$ requires for excitation of the semiconductor with photons, wherefore the formation of the electron-hole pair occurs. Reactions occur in two bands: in the valence band and in the conduction band.

The material proved capable of generate pairs of electrons through absorption wavelengths greater than or equal to $254 \mathrm{~nm}$ in the UV range of the spectrum in order to partially degrade solutions of MB and IB.

Considering the efficiency of the material in the degradation of both solutions, it is possible to classify the $\mathrm{ZnO}$ synthesized by the sol-gel protein route a promising catalyst in the light of existing research.

Table 1 shows the degradation results of dye solutions and other drugs, in order to show that the material efficiency of this work is adequate and promising when compared to others.

The literature ${ }^{23-27}$ also support the theory that the material structure, synthesis and preparation temperature of these materials have a great influence on their catalytic capacity.

\section{Conclusions}

The sol-gel protein route was efficient in the formation of a well-structured, homogeneous and low residue material. It is possible to observe, through XRD and XPS analysis, the absence of residual carbon from the synthesis process, improving the degradability of the material.

The efficiency of photoactivity of the nanomaterials was confirmed by the study of dye degradation via molecular absorption spectrometry in the UV-Vis spectrum region. The degradation percentages obtained were 97 and 60\%, respectively, for MB and IB solutions. It is considered that the use of this substance is an excellent proposition in regions of high consumption of water and high incidence of light.

\section{Acknowledgments}

ECS thanks FAPEAM for financial support, LAP to CNPQ process 429172/2016-8 universal, LPC, to CNPQ process 311461/2017-4, to the Laboratório Temático de Microscopia Optica e Eletronica (LTMOE), from Instituto Nacional de Pesquisas do Amazonas (INPA) and we thank the Photoelectron Spectroscopy Multiuser Laboratory (CT-INFRA FINEP) of IQ-UFRJ for the XPS analysis.

\section{Author Contributions}

Emilly C. da Silva was responsible for performing the research, data interpretation and text writing; Maria O. S. de Moraes for interpreting XPS analyzes; Walter R. Brito for guiding and conducting XPS analyzes; Raimundo R. Passos for research advisor and reviewer; Rodrigo F. Brambilla for guiding and conducting the photocatalysis analysis; Luiz P. da Costa for guiding and conducting the SEM analysis; Leandro A. Pocrifka for research advisor, reviewer and correspondent author. 


\section{References}

1. Azarpira, H.; Abtahi, M.; Sadani, M.; Rezaei, S.; Atafar, Z.; Bay, A.; Mohseni, S. M.; Sarkhosh, M.; Shanbedi, M.; Ghaderpoori, M.; Fakhri, Y.; Keramati, H.; Fanai, V.; J. Photochem. Photobiol., A 2019, 374, 43.

2. Ameen, S.; Akhtar, M. S.; Shin, H. S.; Mater. Lett. 2016, 183, 329.

3. Thongsuriwong, K.; Amornpitoksuk, P.; Suwanboon, S.; Adv. Powder Technol. 2013, 24, 275.

4. Beiraghdar, N.; Talebian, N.; J. Sol-Gel Sci. Technol. 2015, 75, 383.

5. Talebian, N.; Nilforoushan, M. R.; Maleki, N.; Thin Solid Films 2013, 527, 50 .

6. Zhang, L.; Yin, L.; Wang, C.; Lun, N.; Qi, Y.; ACS Appl. Mater. Interfaces 2010, 2, 1769.

7. Zhang, J.; Liu, H.; Wang, Z.; Ming, N.; Li, Z.; Biris, A. S.; Adv. Funct. Mater. 2007, 17, 3897.

8. Roselin, L. S.; Rajarajeswari, G. R.; Selvin, R.; Sadasivam, V.; Sivasankar, B.; Rengaraj, K.; Sol. Energy 2002, 73, 281.

9. Tong, G. X.; Liang, Y.; Hu, Q.; Wu, R. N.; Guan, J. G.; J. Mater. Chem. B 2013, 1, 454.

10. Panigrahi, J.; Behera, D.; Mohanty, I.; Subudhi, U.; Nayak, B. B.; Appl. Surf. Sci. 2011, 258, 304.

11. Ekthammathat, N.; Thongtem, S.; Thongtem, T.; Phuruangrat, A.; Powder Technol. 2014, 254, 199.

12. Szabo', I.; Ne'meth, T.; De'ka'ny, J.; Colloids Surf., A 2003, $230,23$.

13. Omri, A.; Benzina, M.; Bennour, F.; J. Ind. Eng. Chem. (Amsterdam, Neth.) 2015, 21, 356.
14. Silva, R. S.; Macedo, Z. S.; J. Therm. Anal. Calorim. 2011, 103, 587.

15. Etcheverry, L. P.; Flores, W. H.; Silva, D. L.; Moreira, E. C.; J. Mater. Res. 2018, 21, e20170936.

16. Zhang, M.; Xu, K.; Jiang, X.; Yang, L.; He, G.; Song, X.; Sun, Z.; Lv, J.; J. Alloys Compd. 2014, 615, 327.

17. Pawley, G. S.; J. Appl. Crystallogr. 1981, 14, 357.

18. Wojdyr, M.; Appl. Crystallogr. 2010, 43, 1126.

19. Fonseca, V.; Siqueira, R.; Landers, R.; Ferrari, J.; Marana, N.; Sambrano, J.; La Porta, F.; Schiavon, M.; J. Alloys Compd. 2018, 739, 939.

20. Khan, W.; Khan, F.; Ajmal, H. M. S.; Huda, N. U.; Kim, J. H.; Kim, S. D.; Nanomaterials Basel. 2018, 8, 68.

21. Morozov, I. G.; Belousova, O. V.; Ortega, D.; Mafina, M.-K.; Kuznetcov, M. V.; J. Alloys Compd. 2015, 633, 237.

22. Chang, F. M.; Wu, Z. Z.; Huang, J. H.; Chen, W. T.; Brahma, S.; Lo, K. Y.; Nanomaterials 2018, 8, 811.

23. An, S.; Joshi, B. N.; Lee, M. W.; Kim, N. Y.; Yoon, S. S.; Appl. Surf. Sci. 2014, 294, 24.

24. Li, J.; Cheng, Z.; Liu, M.; Zhang, M.; Hu, M.; Zhang, L.; Jiang, H.; Li, J.; J. Appl. Polym. Sci. 2015, 132, 41627.

25. Zhang, S.; Chen, H.-S.; Matras-Postolek, K.; Yang, P.; Adv. Chem. Phys. 2015, 17, 30300 .

26. Khalafi, T.; Buazar, F.; Ghanemi, K.; Sci. Rep. 2019, 9, 6866.

27. El-Kemary, M.; El-Shamy, H.; El-Mehasseb, I.; J. Lumin. 2010, 130, 2327.

Submitted: February 4, 2020

Published online: March 20, 2020 